"Factors influencing the Perceptions of youth entrepreneurship development in South Africa"

AUTHORS

ARTICLE INFO

DOI

RELEASED ON

JOURNAL

FOUNDER
Germinah Evelyn Chiloane-Tsoka

Germinah Evelyn Chiloane-Tsoka (2016). Factors influencing the Perceptions of youth entrepreneurship development in South Africa. Problems and Perspectives in Management, 14(3-2), 556-563. doi:10.21511/ppm.14(3-2).2016.12

http://dx.doi.org/10.21511/ppm.14(3-2).2016.12

Tuesday, 27 September 2016

"Problems and Perspectives in Management"

LLC "Consulting Publishing Company "Business Perspectives"

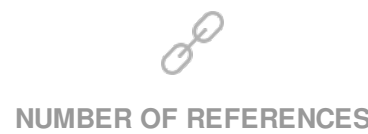

0
NUMBER OF FIGURES

0

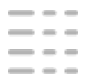

NUMBER OF TABLES

0

(C) The author(s) 2022. This publication is an open access article. 
Germinah Evelyn Chiloane-Tsoka (South Africa)

\title{
Factors influencing the perceptions of youth entrepreneurship development in South Africa
}

\begin{abstract}
Youth unemployment is one of the central concerns affecting global economics in the world today. The recent World Economic Forum held at Davos prioritized the discussions on issues confronting youth unemployment. The International Labor Office (ILO, 2013) projected a global youth unemployment rate of $12.7 \%$ by 2017 . According to the ILO, (2013), 202 million people are unemployed globally and 40\% are under the age of 24. South Africa fares even worse. Statistics SA (2012) indicates that $71 \%$ of the unemployed are aged 25-34 and the unemployment rate among youth is $36 \%$. About 3.3 million youth aged $15-34$ are not employed or studying (Financial Mail, $7^{\text {th }}$ February 2013 ). With this in mind, the paper intends to look at the perceptions affecting youth entrepreneurship development in South Africa and whether entrepreneurial education and training fosters the development of entrepreneurial orientation in the South African youth. A five point Likert Scale was used, $1=$ Strongly disagree $3=$ Neutral and $5=$ Strongly agree. Furthermore, a quantitative research method was used and 132 grade eleven learners were purposefully selected randomly in Crawford high school in Gauteng. Findings indicate that entrepreneurship education and training can direct students towards certain career choices; secondly, planned behavior can be predicted; and thirdly, practically is able to increase the propensity of students to start a business.
\end{abstract}

Keywords: SA, learners, entrepreneurship culture, orientation, education, youth unemployment. JEL Classification: L26, J24.

\section{Introduction}

The Global Entrepreneurship Monitor (GEM, 2011) estimates that 388 million entrepreneurs were actively engaged in starting or running new businesses in 2011. A report by GEM (2011) in Global report of 2011 indicated that the Total Enterprise Activity (TEA) in South Africa remains lower than that of the average of the 54 economies that participated in the survey of GEM 2011. The results reflected significantly below that of the average of all middle- to low-income countries. According to the survey data of GEM, a country at South Africa's stage of economic development would be expected to have a TEA rate in the order of $15 \%$, over $60 \%$ more than South Africa's actual rate of $8.9 \%$ (GEM South African Report, 2010). A further area of concern is the low involvement in early stage entrepreneurial activity in the 18-24 years and 25-34 years age categories, reported in the (GEM, 2010) South African report. Although the involvement percentages of $20 \%$ and $36 \%$, respectively, in the two youth age categories, are in line with the general GEM trends, it is of particular concern in the South African context, as the youth represent a high proportion of the total population in South Africa (GEM South African Report, 2010).

In his study, Schoof (2006) asserts that entrepreneurship education is crucial in assisting young people to develop entrepreneurial skills, attributes and behaviors, as well as to develop enterprise awareness, to understand and to realise

(c) Germinah Evelyn Chiloane-Tsoka, 2016.

Germinah Evelyn Chiloane-Tsoka, School of Operation and Management sciences, University of South Africa, South Africa. entrepreneurship as a career option. In his argument, Schoof (2006) further contends that entrepreneurship education is not only a means to foster youth entrepreneurship and self-employment, but at the same time to equip young people with the attitudes (e.g., more personal responsibility) and skills (e.g., flexibility and creativity) necessary to cope with the uncertain employment paths of today's societies. "Young people can no longer expect to find the traditional 'job-for-life' careers, but rather 'portfolio careers' (contract employment, freelancing, periods of self-employment, etc.). Enterprise education is, therefore, seen as a highly valuable preparation for the changing job market and economy in which young people have to operate" (Schoof, 2006, pp. 34-35). In order to determine whether education and training fosters entrepreneurial development in SA it was important to: (i) establish if entrepreneurial training and education fosters entrepreneurial orientation in the youth, (ii) establish whether risk associated with entrepreneurship is a deterrent to entrepreneurial orientation, (iii) whether role models assist youth to start and grow business.

\section{Background}

According to the Western Cape Youth Report (2008), preliminary research has suggested that entrepreneurship education can have a significant positive influence on four areas crucial to entrepreneurship. These include the learners' selfconfidence about their ability to start a business, the learners' understanding of financial and business issues, the learners' desire to start their own business and the learners' desire to undertake higher education. While the Western Cape Youth Report 
(2008), articulates problems with education and training as a major inhibitor of entrepreneurial growth in the economy. The report suggests that the legacy of apartheid education influenced basic skills levels in two areas. Firstly, vast numbers of people, particularly Blacks, missed out on the opportunity of a decent education, which severely affected their ability to interact with the mainstream economy. A second level, on which the impact of apartheid education is still being felt, according to the report, is in the on-going difficulties experienced with the poor quality of education in South Africa. Steenekamp (2011) believes that entrepreneurship education should be seen as a vehicle to promote business start-up on at least three levels: firstly, at the attitudinal level directing students towards certain career choices; secondly, at the intentional level where planned behavior can be predicted; and thirdly, at the practical level where it increases the propensity of students to start a business.

Whereas in a study conducted by Fatoki \& Chindoga (2011, p. 166) an observation of the obstacles towards youth entrepreneurship was accorded to lack of business culture in most university graduates. Universities and high schools should be used as sources of information to students about entrepreneurial opportunities. In their argument, they further alluded that entrepreneurship should be encouraged and embedded in education from early formative years through secondary education. In the findings of a research conducted by Bheeka \& Rimmington (2011), it was found that entrepreneurs who were more developed (educationally) had expertise that lowered their barriers to entry into more specialized business sectors. These entrepreneurs were also able to grow their business sufficiently in order to offer employment to others, while the least educated entrepreneurs operated businesses in the informal sector where they were more vulnerable to environmental shifts. And lacked out on entrepreneurship curriculum development in all stages of their education and had no subjects of entrepreneurship could not flourish in their business. The finding correlates with the findings of the GEM 2010 report, which indicates that there is a strong positive relationship between the level of education of the entrepreneur and the level of business success. Thus, Rasheed (2002) concludes that entrepreneurship education and enterprise experience can affect characteristics commonly associated with entrepreneurs among intermediate level students (prior to the tertiary education level). On the other hand, Walstad \& Kourilsky (1999) investigated the attitudes towards, education and knowledge of entrepreneurship among black youth, and the observation of the findings found that the low level of knowledge about entrepreneurship were a major problem for the youth and in particular the African Blacks. They asserted that entrepreneurship education is essential if youth are to overcome the low level of knowledge and misperceptions about how markets work (Walstad \& Kourilsky, 1999).

\subsection{Factors contributing towards educational} constraints of entrepreneurship. Schoof (2006) found that the following factors were the key educative constraints to entrepreneurship:

- general lack of introduction and adoption of enterprise education - in many countries, particularly in developing and transition countries, enterprise education simply does not exist or has not been sufficiently adopted;

- inadequate curricula and study program - the teaching of entrepreneurial skills and attributes and behaviors is often not properly integrated into school curricula or not adequately taught on different educational levels;

- wrong learning methods - in most education systems, there is still a clear lack of practical and experiential learning, as well as of teamwork learning;

- negligence of students' personal environment entrepreneurship education initiatives often disregard the important role of family members of young people and their parents in particular;

- lack of trained/educated teachers - teachers and university professors often have only limited experience in, and understanding of, small businesses and self-employment;

- lack of career information and business possibilities - school environments often do not sufficiently introduce youth to the concept of entrepreneurship and self-employment as a career option; and

- lack of business and education linkages relationships between educational institutions and the business community (school-industry partnerships, combination of classroom learning and structured on-the-job experience) do not exist or are poorly developed, as well as lack of information and communication technology ICT infrastructure and financial constraints.

1.2. Perceptions of risk and failure as challenges towards educational constraints facing youth entrepreneurs. Fatoki and Chindoga (2011) state that one of the obstacles to the success of an enterprise, was the lack of willingness to take risks. Whereas Kazela (2009, as cited in Fatoki \& Chindoga, 2011) suggested that many young entrepreneurs become risk averse because of their social environment. According to the Western Cape Youth Report (2008), research findings indicated that $40 \%$ of respondents were likely 
to not start a business due to a fear that the business might fail. According to the GEM 2010 report, an inhibiting factor noted in numerous South African GEM reports was the harsh attitude towards failures which inhibited many potential entrepreneurs. The GEM 2010 report further asserts that while much about entrepreneurship can be taught or acquired through practical experience, propensity for risk cannot. Risk-taking propensity can, therefore, play a significant role in the transition from potential or nascent entrepreneurship to actual business start-up.

1.3. Role model as determinants of youth entrepreneurial education and training. The influence of role models on entrepreneurial orientation plays a critical role in influencing youth development. Steenekamp et al. (2011), while investigating youth entrepreneurship in selected South African high schools, have found that having entrepreneurial role models did not increase entrepreneurial orientation in the students surveyed. In the same study, Steenkamp et al. (2011) found that although the majority of learners saw good opportunities in South Africa to start a business and perceived entrepreneurship as a desirable career choice, only one-third of learners actually planned to start a business as soon as they had finished school. According to the Western Cape Youth Report (2008), young people, particularly, need to be encouraged to see entrepreneurship as a potential career option. While GEM research has shown that personally knowing someone that has started a business can have a positive influence on entrepreneurial attitudes, this statement should be qualified by indicating that knowing someone that has a positive perception of starting a business could have a positive influence on entrepreneurial attitudes. Fifty one percent of necessity businesses indicated that people that start their own business have to work too hard for very little money. Knowing necessity business owners may, therefore, not have a positive influence on entrepreneurial attitudes.

\section{Problem statement}

The 2008 Western Cape youth report provides fundamental problems influencing perceptions of youth to engage in entrepreneurship activities being many and varying from different facets. It is primarily reasons of a lack of access to finance, lack of awareness of government program and initiatives aimed at assisting the youth, the poor management of these program and the inadequacy of the South African education system to produce functionally literate students that are able to participate actively in the economy. Inadequate education system is also a factor constraining youth entrepreneurship development in South Africa. Lack of role models and risk factor for starting business are among others prone to failure of youth business ventures. Although youth entrepreneurial initiative has long been accepted as a possible solution to the high levels of unemployment in South Africa, and had prompted the formation of the National Youth Development Agency (NYDA) in June 2009. According to the then NYDA's Chief Executive Officer (CEO), Steven Ngubeni, the agency's approach to youth unemployment is structured on three interventions; education, entrepreneurial assistance and job placement initiatives. It has been stated that South Africa seems to be lagging in terms of entrepreneurial initiative regardless of all endeavors to make entrepreneurial success. Especially of the fact that South Africa has seemingly failed to develop the "culture of entrepreneurship" that has taken to be characteristic of many other middle-income developing countries, thus, this study intends: to determine if entrepreneurial education and training fosters the development of youth entrepreneurial orientation in South African.

\section{Research methodology}

According to Salkind (2012, p. 10), there are three dimensions, including the nature of the question asked, the method used to answer it and the degree of precision the method brings to answering the question, will determine the research methodology to be used in a particular study. A quantitative research approach was followed and, according to Leedy and Ormrod (2001), this is regarded as the most appropriate approach for the research, because this type involves acquiring information about a group of people, namely youth in selected high school in Gauteng. The research designed was used to determine the extent to which entrepreneurial training and educations at secondary school level fosters a culture of entrepreneurship in the South African youth. According to Salkind (2012), correlational research as a descriptive technique is very powerful, because it indicates whether variables share something in common with each other. If they do, the two are correlated with one another. Correlational research is an appropriate research design, as the study seeks to establish if a relationship exists between entrepreneurial training and education and entrepreneurial orientation. Both Correlations and Independent Samples T-test were the selected statistical methods employed. The $p$-value was used to ascertain whether a relationship existed and was used to address the empirical objectives.

3.1. Questionnaire design. A self-administered questionnaire was selected as the research instrument, because it saved time and pupils were able to complete them without any direct assistance or intervention. The added advantage of a questionnaire is that it could be emailed to respondents for completion. However, since the data source is high school students, the pen-and-paper based option was used. To cater for the disadvantage of a lower 
response rate, when compared to the interview technique, all pupils in the entire grade $(\mathrm{N}=132)$ were surveyed. Since the high school selected is an English median school and pedagogy is conducted in English, the questionnaire was developed in English only. To obtain access to the pupils, a request was sent to the college principal, firstly, requesting permission to survey the pupils and requesting that Life Orientation (LO) teachers hand out the questionnaire for completion during each grade 11 class's LO lesson in the week $2^{\text {nd }}$ to $6^{\text {th }}$ September 2013.

3.2. Sampling. All grade 11 pupils at Crawford College Lonehill were selected as the sample $(\mathrm{N}=132)$. This type of sampling is referred to as convenience sampling, which is a non-probability sampling technique where subjects are selected because of their convenient accessibility and proximity to the researcher. Advantages of convenience sampling include that it is very easy to carry out with few rules governing how the sample should be collected, the relative cost and time required to carry out a convenience sample is small in comparison to probability sampling techniques and the convenience sample may assist in gathering useful data and information that would not have been possible using probability sampling techniques, which require more formal access to lists of populations.
3.3. Pilot testing. The survey was piloted with 3 students to test the flow of the questionnaire, identify and eliminate ambiguous or difficult questions and verify the time taken to complete. The sample data were captured as part of a process used to verify that the necessary data produced will allow the addressing of the empirical objectives.

3.4. Issues of reliability. The internal consistency, which examines the one-dimensional nature of a set of items, Cronbach's Alpha coefficients and intercorrelation coefficients were used to assess reliability of the measuring instrument (Salkind, 2012, p. 122). The result obtained from the iterative reliability analysis of the Entrepreneurial Culture Survey (ECS) initially yielded a Cronbach's Alpha of 0.692 based on 19 items. Cronbach's Alpha of 0.692 is slightly below the agreed upon lower limit of 0.70 . Two questions ( 21 and 22) were, therefore, removed to achieve the required lower limit.

The subsequent result obtained from the iterative reliability analysis of the ECS yielded a Cronbach's Alpha of 0.734 based on 17 items, indicating an acceptable reliability. All Corrected Item-Total Correlations are above 0.3 indicating sufficient correlation of each item with the overall factor. It can also be seen that removal of any question will not improve on the already attained Cronbach's Alpha. A total of 17 items were tested for their reliability and the Cronbach's Alpha was $=0.734$

Table 1. Cronbach's Alpha reliability analysis on entrepreneurial culture survey

\begin{tabular}{|l|c|c|}
\hline \multicolumn{1}{|c|}{ Item-total statistics } & Corrected item-total correlation & Cronbach's Alpha if item deleted \\
\hline Q9 Being an entrepreneur would provide a good living & 0,315 & 0,723 \\
\hline Q10 Becoming an entrepreneur would be easy & 0,094 & 0,741 \\
\hline Q11 I aspire to be an entrepreneur & 0,653 & 0,688 \\
\hline Q12 In general, I have heard good things about entrepreneurs & 0,419 & 0,715 \\
\hline Q13 I would be comfortable running my own business & 0,495 & 0,705 \\
\hline Q14 Someone who runs their own business is successful & 0,069 & 0,743 \\
\hline Q23 I am willing to put the time in that it takes to be an entrepreneur & 0,535 & 0,700 \\
\hline Q24 I would enjoy the lifestyle provided by being an entrepreneur & 0,653 & 0,691 \\
\hline Q25 Being an entrepreneur would better my lifestyle when I retire & 0,372 & 0,718 \\
\hline Q26 Being a successful entrepreneur would increase my wealth & 0,446 & 0,711 \\
\hline Q27 Entrepreneurship has a positive impact on the country's economy & 0,334 & 0,722 \\
\hline Q19 Becoming a successful entrepreneur is simply having enough money to start. [R] & 0,049 & 0,748 \\
\hline Q28 I do not know anyone who could mentor/help me be an entrepreneur [R] & 0,370 & 0,740 \\
\hline $\begin{array}{l}\text { Q29 I do not know any institutions (schools/universities) that could educate/qualify me } \\
\text { to be an entrepreneur [R] }\end{array}$ & 0,140 & 0,723 \\
\hline Q30 I do not know how I would get money to start a business [R] & 0,316 & 0,746 \\
\hline Q31 One needs a specific education to be a successful entrepreneur [R] & 0,061 & 0,730 \\
\hline Q32 Someone who fails in starting a business is not an entrepreneur [R] & 0,238 & \\
\hline
\end{tabular}

Note: $[R]$ denotes reversed question.

The Cronbach's Alpha coefficient indicates that the overall scales have an accepted reliability and can consistently measure the particular dimensions of the magnitude they are designed to measure. In other words, the measuring instruments are capable of consistently reflecting the same underlying constructs. Furthermore, this consistency indicates a high degree of homogeneity between the questionnaire's items. 


\section{Data analysis}

The Statistical Package for the Social Sciences (SPSS) software program was used to perform statistical analysis for this study. Descriptive statistics such as frequency distribution of scores, measures of central tendency (mean, median, and mode), and measures of variability (range and standard deviations) were used to analyze and describe the data, i.e., the degree to which entrepreneurial education and training impact on entrepreneurial orientation. Once the data were described and statistical reliability established, inferential statistics was applied to test the hypotheses established.

The Pearson correlation coefficient was used to measure the degree of relationship between entrepreneurial education and training and entrepreneurial orientation. The method for interpreting the correlation coefficient by squaring its value and, then, computing the coefficient of determination was employed. Effect sizes were used to decide on the practical significance of the findings, where 0.10 was regarded as a small effect, 0.30 as a medium effect and 0.50 as a large effect (Cohen, 1988).

4.1. Ethical consideration. Confidentiality of respondents was ensured by guaranteeing their anonymity. Respondents were advised that all information provided will be compiled at the aggregate level with no way of determining the identity of respondents. The principal to invited students to participate in the study. Furthermore, an informed consent form that was read and signed by each participant was included with the survey. The consent form contained, among other information, the purpose of the research, an offer to withdraw from the experiment at any time for any reason, an assurance that the results will be kept in strictest confidence, the means for the participant can get a copy of the result and how the researcher can be reached should questions arise.

4.2. Discussion at descriptive level. The findings of the research are discussed in detail below. The primary research objective of the study was to investigate the relationships between entrepreneurial training and education and entrepreneurial orientation. For the purpose of hypothesis testing of the primary research objective the selection of Business Studies as a subject to be studied, as well as a set of questions dealing with entrepreneurial orientation in the Entrepreneurial Culture Survey (ECS) was used.

4.3. Hypotheses testing. Inferential testing will be carried out through the utilization of Independent Samples T-Tests and Correlations in order to address the research objectives, namely:
- investigate the relationship between entrepreneurial training and education and entrepreneurial orientation:

- determine if perceived risk associated with entrepreneurship has an impact on entrepreneurial orientation:

- determine if respondents are more entrepreneurially oriented if they have friends/acquaintances that are entrepreneurs.

According to Pallant (2011), Independent Samples T-Tests are used when there are two different (independent) groups, and there is an interest in comparing their scores. The Independent Samples T-Test compares the means of one variable for two groups of cases (SPSS Inc., 2005). If the $p$-value is found to be less than 0.05 , then, the independent variable in question does have a significant relationship with the factor at hand. Norusis (2005) suggests that if the p-value is small enough (less than 0.05), then, the null hypothesis can be rejected.

4.4. Hypothesis one. $H_{0}$ - having selected Business Studies as a subject to be studied has no impact on entrepreneurial orientation.

$H_{1}$ - having selected Business Studies as a subject to be studied has an impact on entrepreneurial orientation.

Table 2. Hypothesis testing one - group statistics

\begin{tabular}{|l|l|c|c|c|}
\hline $\begin{array}{c}\text { Subjects (group 2): } \\
\text { business studies }\end{array}$ & & $\mathrm{N}$ & Mean & $\begin{array}{c}\text { Standard } \\
\text { deviation }\end{array}$ \\
\hline $\begin{array}{l}\text { Entrepreneurial } \\
\text { orientation }\end{array}$ & Not selected & 49 & 3.5114 & 0.50305 \\
\cline { 2 - 5 } & Selected & 64 & 3.7574 & 0.44063 \\
\hline
\end{tabular}

The above table brings the variables together showing the entrepreneurial score for respondents that had selected Business Studies and those who had not.

Table 3. Hypothesis testing one - Independent Samples T-test

\begin{tabular}{|l|c|c|c|c|}
\hline & $\begin{array}{c}\text { T- } \\
\text { statistic }\end{array}$ & $\begin{array}{c}\text { Degrees of } \\
\text { freedom }\end{array}$ & $\begin{array}{c}p- \\
\text { value }\end{array}$ & $\begin{array}{c}\text { Mean } \\
\text { difference }\end{array}$ \\
\hline $\begin{array}{l}\text { Entrepreneurial } \\
\text { orientation }\end{array}$ & -2.765 & 111 & 0.007 & -.24595 \\
\hline
\end{tabular}

The above table brings into account the result of the Independent Samples T-test. As reflected the $p$-value is significant $(<0.05)$. Therefore, the null hypothesis can be rejected. This implies that taking Business Studies as a subject to be studied does have an impact on entrepreneurial orientation.

Also, as indicated by the chart below, the mean score for entrepreneurial orientation is higher for respondents that had selected Business Studies at 3.7574 compared to 3.5114 for respondents that had not selected Business Studies. 


\section{Entrepreneurial orientation}

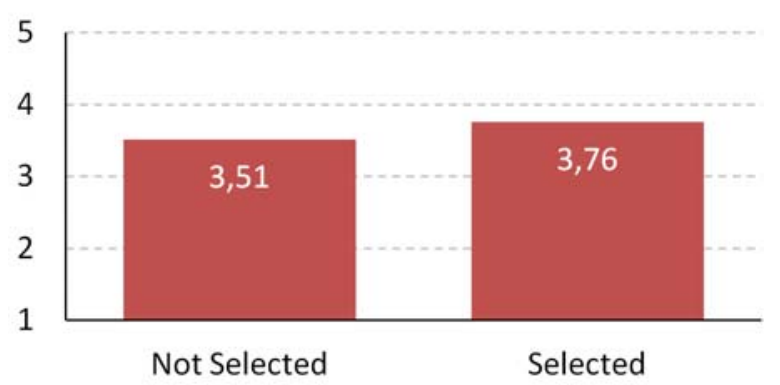

Subjects (group 2): business studies

Fig. 1. Hypothesis testing one - mean score

4.4. Hypothesis two. $H_{0}$ - there is no relationship between risk and entrepreneurial orientation.

$H_{1}$ - there is a relationship between risk and entrepreneurial orientation.

Table 4. Hypothesis testing two - correlations

Q15 There is a lot of risk in starting and running your own business

\begin{tabular}{|l|l|c|}
\hline \multirow{3}{*}{$\begin{array}{l}\text { Entrepreneurial } \\
\text { orientation }\end{array}$} & Pearson correlation & 0.119 \\
\cline { 2 - 3 } & $p$-value & 0.211 \\
\cline { 2 - 3 } & $\mathrm{N}$ & 113 \\
\hline
\end{tabular}

The above table reflects the correlation between risk and entrepreneurial orientation, the $p$-value is not significant i.e., not $<0.05$. The null hypothesis can, therefore, not be rejected. Thus, there is no relationship between risk and entrepreneurial orientation.

4.4. Hypothesis three. $H_{0}$ - There is no impact on entrepreneurial orientation if respondents have friends/acquaintances that are entrepreneurs.

$H_{1}$ - There is an impact on entrepreneurial orientation if respondents have friends/acquaintances that are entrepreneurs.

For ease of analysis, recoding took place resulting in only two categories of values (None or 1+) relating to the analysis for number of friends/acquaintances.

Table 5. Hypothesis testing three - frequency

\begin{tabular}{|l|c|c|c|}
\hline \multicolumn{4}{|c|}{ Q7 Number of friends/acquaintances you know who run their own business } \\
\hline \multirow{3}{*}{ Valid } & & Frequency & Percent \\
\hline & None & 47 & 41.6 \\
\cline { 2 - 4 } & $1+$ & 66 & 58.4 \\
\cline { 2 - 4 } & Total & 113 & 100.0 \\
\hline
\end{tabular}

The table below brings the variables together showing the entrepreneurial orientation score for respondents that had friends/acquaintances as entrepreneurs and those who had not.

Table 6. Hypothesis testing three - group statistics

\begin{tabular}{|l|c|c|c|c|}
\hline $\begin{array}{l}\text { Q7 Number of friends/acquaintances you } \\
\text { know who run their own business }\end{array}$ & $\mathrm{N}$ & Mean & $\begin{array}{l}\text { Standard } \\
\text { deviation }\end{array}$ \\
\hline \multirow{2}{*}{ Entrepreneurial orientation } & None & 47 & 3.5131 & 0.52207 \\
\cline { 2 - 5 } & $1+$ & 66 & 3.7487 & 0.42961 \\
\hline
\end{tabular}

Table 7. Hypothesis testing three - independent samples T-test

\begin{tabular}{|l|c|c|c|c|}
\hline $\begin{array}{c}\text { Equal variances } \\
\text { assumed }\end{array}$ & T-statistic & $\begin{array}{c}\text { Degrees of } \\
\text { freedom }\end{array}$ & $p$-value & $\begin{array}{c}\text { Mean } \\
\text { difference }\end{array}$ \\
\hline $\begin{array}{l}\text { Entrepreneurial } \\
\text { orientation }\end{array}$ & -2.625 & 111 & 0.010 & -.23552 \\
\hline
\end{tabular}

Note: * $p$-value $(<0.05)$.

Indicates a significant level, therefore, the null hypothesis is rejected. This implies that having friend/acquaintances as entrepreneurs does have an impact on entrepreneurial orientation.

4.5. Review of empirical objectives. The primary research objective of the study was to investigate the relationship between entrepreneurial training and education and entrepreneurial orientation.

The research objectives at the secondary level were as follows:

1. Research objective 1: determine if perceived risk associated with entrepreneurship has an impact on entrepreneurial orientation.

2. Research objective 2: determine if respondents are more entrepreneurially oriented if they have relatives/acquaintances that are entrepreneurs.

4.6. Addressing the empirical research objectives. The three empirical research objectives were addressed.

1. Investigate the relationship between entrepreneurial training and education and entrepreneurial orientation.

For the purpose of hypothesis testing of the primary research objective, the selection of Business Studies as a subject to be studied implied the existence of entrepreneurial training and education. Selected questions in the Entrepreneurial Culture Survey (ECS) were used to gauge entrepreneurial orientation. At the item level it was seen that the majority of the questions (14 out of 24) experienced higher than average mean values, i.e., a positive inclination towards entrepreneurial orientation. Since the Likert scale was divided into five categories, the middle category (" 3 ") indicated a neutral response to the question. More of the items in this case scored higher than " 3 ", suggesting an overall positive inclination to entrepreneurial orientation.

It was also found that the mean score for entrepreneurial orientation was higher for respondents that had selected Business Studies at 3.7574 compared to 3.5114 for respondents that had not selected Business Studies, implying that taking Business Studies as a subject to be studied does have an impact on entrepreneurial 
orientation. This finding correlates with the research findings in the literature reviewed.

2. Determine if perceived risk associated with entrepreneurship has an impact on entrepreneurial orientation.

Responses to Question 15 (There is a lot of risk in starting and running your own business) in the Entrepreneurial Culture Survey were used to determine if perceived risk associated with entrepreneurship had an impact on entrepreneurial orientation. It was found that perceived risk associated with entrepreneurship did not have an impact on entrepreneurship orientation. This finding is contrary to the research findings in the literature reviewed.

3. Determine if respondents are more entrepreneurially oriented if they have relatives/acquaintances that are entrepreneurs.

For ease of analysis, only two categories of values (None or 1+) relating to the number of friends/acquaintances were analyzed. The mean score for respondents that had at least 1 friend/acquaintance as an entrepreneur at 3.7487 was higher compared to 3.5131 for respondents that had no friends/acquaintances as entrepreneurs. This finding implies that respondents are more entrepreneurially oriented if they have relatives/acquaintances that are entrepreneurs. This finding is contrary to the research findings in the literature reviewed.

\section{Recommendations}

- While there are many factors influencing entrepreneurial orientation in the South African youth, a focus on entrepreneurship education and training would have far reaching positive consequences. Entrepreneurial education and training not only develop practical skills (e.g., financial acumen and marketing skills), but also develop soft skills such as creativity, innovation and risk-taking which are crucial for the interpretation of successful entrepreneurial role models and identification of business opportunities.

- To foster entrepreneurship development, it is suggested that entrepreneurship be encouraged and embedded in education from early formative years through secondary education and be part of the curriculum in all stages of education and all subjects.

- To achieve this objective, it is recommended that teachers are trained in entrepreneurial and commercial skills. Financial literacy has long been accepted as a critical skill contributing to the success of entrepreneurial business ventures.
- To develop entrepreneurial financial skills and competencies, it is recommended that educational institutions work with organizations such as the South African Banking Association to develop training material focusing on financial skills and competencies. Further, previous research on high school and university students had identified a skills mismatch between the skills developed in higher education and what is actually needed in the business world.

- To bridge this gap, it is recommended that university and high school students undergo industrial attachment (work experience placement) for a period during their studies. Industrial attachment is an opportunity for students to develop their skills beyond the classroom and to build confidence before entering the competitive business world. This research determined that the presence of entrepreneurial role models does have a positive impact on entrepreneurial orientation. It is, therefore, recommended that educational institutions introduce a mentorship approach to help students to get practically involved in entrepreneurial ventures.

\section{Limitations of the study and areas for future research}

- The study was mainly based on the perceptions of the youths. A limitation might arise in that possible differences may exist between perception and reality. Only one high school located in a metropolitan area was utilized in the study, thus, limiting the generalization to other high schools, Although a generally understood limitation,

- The sampling method applied in this study was unavoidable and limited in scientific terms. Another limitation of this study is that it investigated the perceptions of youth who are in the education system.

- Subsequent studies can investigate the barriers faced by actual entrepreneurs (i.e., youths that have actually started their business). This could help to reduce the high failure rate of small entrepreneurial firms in South Africa.

- Since the study's sampling was described as convenient, only a once-off perceptions gauge was acquired.

\section{Further study}

- Future studies should incorporate other high schools, including those in rural areas, in order to compare the results and be able to generalize the findings.

- Further studies into factors influencing youth entrepreneurship could be conducted on the youth who are out of school and who are jobless. 
- Longitudinal studies of this nature would be extremely valuable especially in terms of entrepreneurial intentions, where the intentions may result in actual behavior.

\section{Conclusion}

This study answered all the research questions that were set out and the following were conclusions: education is vital in creating an understanding of entrepreneurship, developing entrepreneurial capababilities, and contributing to entrepreneurial identities and cultures at individual, collective and social level. The study also provided a platform of understanding the role of mentors or role models as a priority in encouraging entrepreneurial ventures. This concurred with the findings of Botha (2014) The study also depicted the role of education as a stepping stone towards shaping ideas of what it means to be an entrepreneur, not just to promote an ideology of entrepreneurship, but to create a critical awareness that contributes to the accountability of entrepreneurs in the society at large. Meaning that life skills and entrepreneurial encouragement should be an integral part of the school curriculum. Different scholars and expercts suggested that potential entrepreneurs will find these skills invaluable when they are later coupled with their acquired working expertise and experience. Universities and colleges should be seen fostering appropriate "graduate attributes" such as critical thinking, integrity, innovation, self-motivation, lifelong learning skills, etc. Business skills should be taught at every level. Basic skills should be included in primary and secondary education curricula and business basics should be mandatory at the tertiary level, regardless of chosen fields of study. Descriptive overview of the youth South African entrepreneurial environment can serve as the baseline for future work in South Africa. It was also established that entrepreneurial education and training had a positive impact on entrepreneurial orientation. Finally, the statistical evidence indicated that risk associated with entrepreneurship was not a deterrent to entrepreneurial intentions. It showed that entrepreneurial role models had a positive impact on entrepreneurial orientation.

\section{References}

1. Beeka, B. \& Rimmington, M. (2011). Entrepreneurship as a career option for African youths, Journal of Developmental Entrepreneurship, 16 (1), pp. 145-164.

2. Fatoki, O. \& Chindoga, L. (2011). An Investigation into the Obstacles to Youth Entrepreneurship in South Africa, International Business Research, 4 (2), pp. 161-169.

3. Global Competitiveness Report. (2010/11). World Economic Forum.

4. Global Entrepreneurship Monitor. (2008). 2008 Global Report South Africa. Cape Town: University of Cape Town.

5. Global Entrepreneurship Monitor. (2010). 2010 Global Report South Africa. Cape Town: University of Cape Town.

6. Global Entrepreneurship Monitor. (2011). 2011 Global Report. Babson Park, M.A.: Babson College, Santiago, Chile: Universidad del Desarrollo, Kuala Lampur, Malaysia: Universiti Tun Abdul Razak and London, U.K.: London Business School.

7. National Treasury. (2011). Confronting youth unemployment: policy options for South Africa, Discussion Paper for Public Comment.

8. Norusis, M.J. (2005). SPSS 14.0 Statistical Procedures Companion. New Jersey: Prentice Hall.

9. Pallant, J. (2011). SPSS Survival Manual: A step by step guide to data analysis using SPSS. $4^{\text {th }}$ ed. New South Wales: Allen \& Unwin.

10. Salkind, N.J. (2012). Exploring Research. $8^{\text {th }}$ ed. University of Kansas: Pearson.

11. Schoof, U. (2006). International Labor Office - Geneva. Stimulating Youth Entrepreneurship: Barriers and incentives to enterprise start-ups by young people, Socio-Economics and the Environment in Discussion (SEED) Working Paper No. 76, Series on Youth and Entrepreneurship.

12. SPSS Inc. (2005). SPSS Base 14.0 User's Guide. Chicago: SPSS, Illinois.

13. Steenekamp, A.G., van der Merwe, S.P. \& Athayde, R. (2011). An investigation into youth entrepreneurship in selected South African secondary schools: An exploratory study, Southern African Business Review, 15, pp. 46-75.

14. Swanepoel, E. (2008). The effect of the interventions of the South African Breweries' KickStart Youth Entrepreneurship Programme on entrepreneurial and small business performance in South Africa. (Thesis UNISA).

15. Rasheed, H.S. (2002). Developing Entrepreneurial Characteristics in Youth: The Effects of Education and Enterprise Experience, International Journal of Entrepreneurship Education.

16. Walstad, W.B. \& Kourilsky, M.L. (1999). Entrepreneurial Attitudes and Knowledge of Black Youth. ET\&P, Baylor University.

17. Western Cape Status of the Youth Report. (2008). Graduate School of Business, University of Cape Town. 